Cahiers $d u$ MONDE RUSSE

\section{Cahiers du monde russe}

Russie - Empire russe - Union soviétique et États indépendants

$46 / 1-2 \mid 2005$

La Russie vers 1550

\title{
ГОРОД И ВЕЧЕ
}

\section{Pavel V. Lukin}

\section{OpenEdition \\ Journals}

Édition électronique

URL : https://journals.openedition.org/monderusse/8790

DOI : $10.4000 /$ monderusse. 8790

ISSN : $1777-5388$

Éditeur

Éditions de l'EHESS

Édition imprimée

Date de publication : 1 janvier 2005

Pagination : 157-166

ISBN : 2-7132-2055-6

ISSN : $1252-6576$

\section{Référence électronique}

Pavel V. Lukin, «Город и вече », Cahiers du monde russe [En ligne], 46/1-2 | 2005, mis en ligne le 01 janvier 2007, consulté le 02 septembre 2022. URL : http://journals.openedition.org/monderusse/8790 ; DOI : https://doi.org/10.4000/monderusse.8790 


\section{CAIR N}

chercher : repérer : avancer

Cet article est disponible en ligne à l'adresse :

http://www.cairn.info/article.php?ID REVUE=CMR\&ID NUMPUBLIE=CMR 461\&ID ARTICLE=CMR 4610157

\section{Город и вече}

par Pavel V. LUKIN

\section{| Editions de l'EHESS | Cahiers du monde russe}

\section{5/1-2 - Vol 46}

ISSN 1252-6576 | ISBN 2713220556 | pages 157 à 166

Pour citer cet article :

- V. LUKIN P., Cahiers du monde russe 2005/1-2, Vol 46, p. 157-166.

Distribution électronique Cairn pour les Editions de l'EHESS.

(C) Editions de l'EHESS. Tous droits réservés pour tous pays.

La reproduction ou représentation de cet article, notamment par photocopie, n'est autorisée que dans les limites des conditions générales d'utilisation du site ou, le cas échéant, des conditions générales de la licence souscrite par votre établissement. Toute autre reproduction ou représentation, en tout ou partie, sous quelque forme et de quelque manière que ce soit, est interdite sauf accord préalable et écrit de l'éditeur, en dehors des cas prévus par la législation en vigueur en France. Il est précisé que son stockage dans une base de données est également interdit. 
ПАВЕЛ В. ЛУКИН

\title{
ГОРОД И ВЕЧЕ: СОЦИАЛЬНЫЙ АСПЕКТ
}

\author{
ИСТОРИОГРАФИЧЕСКИЕ ЗАМЕТКИ *
}

Проблема социальной сущности древнерусского веча возникла не одновременно с рождением русской исторической науки. Так, Н. М. Карамзин специального внимания этому вопросу не уделял. При этом он вовсе не отрицал роли веча или политической деятельности горожан в истории Древней Руси, его просто значительно больше интересовала история «единодержавия». С. М. Соловьев также уделял вечу лишь немного внимания, и его замечания на сей счет носят довольно туманный характер.

Подлинное «рождение» проблемы относится к 60-70-х гг. XIX в., когда была сформулирована т.н. земско-вечевая или общинно-вечевая теория. Классическим трудом стало опубликованное в 1867 г. сочинение автора этой теории В. И. Сергеевича Вече и князь, впоследствии неоднократно переиздававшееся и перерабатывавшееся в основном как часть более общего исследования Русские юридические древности. Сергеевич полагал, что «участие в вечевых собраниях понималось в древности как п р а в о, принадлежащее свободному человеку». И далее отмечал: «На вечевых собраниях имеет право участвовать все свободное население волости». Земско-вечевая теория пользовалась практически безраздельным господством во второй половине XIX - начале XX в. Ее, с теми или иными вариациями, придерживались почти все исследователи, занимавшиеся как общими политико-правовыми проблемами, так и историей отдельных русских земель. Чуть ли не каждая работа такого рода начиналась с изложения истории веча в данной области.

\footnotetext{
* Статья подготовлена при поддержке РГНФ (Российский гуманитарный научный фонд), проект № 05-01-01074а и Фонда содействия отечественной науке.

1. В. И. Сергеевич, Русские юридические древности, СПб, 1900, Т. 2: Вече и князь:
} Советники князя, с. 52, 55.

Cahiers du Monde russe, 46/1-2, Janvier-juin 2005, p. 157-166. 
Интересно при этом, что для большинства русских историков досоветского периода проблемы социальной сущности, социального состава веча казались совершенно ясными, раз и навсегда решёнными Сергеевичем, и поэтому как правило специально не рассматривались. Между тем многие положения земско-вечевой теории остались лишь постулированными, но не доказанными. Прежде всего, это касается тезиса об участии в вече всего свободного населения волости, которое подразумевает широкие социальнополитические права в том числе и сельских жителей. Выдвигая это положение, историки обычно исходили из общих соображений. Даже такой осторожный и чрезвычайно внимательный к источникам исследователь, как А. Е. Пресняков вместо тщательного анализа летописных сообщений заявлял :

Главный город стал представителем земли ; его вече - верховной властьн волости. В идее - это народное собрание всей волости; и пригорожане, на чтс имеются прямые указания, и, вероятно, хотя указаний нет, вообе свободны жители земли могли участвовать на вече... 2 .

В советское время сформировались три основные концепции о социальной сущности веча и соответственно три точки зрения на его состав. Их приверженцы вели между собой жаркие споры. Однако все три концепции исходили в той или иной степени из «внеисточниковых» теорий.

Во-первых, высказывалась идея о типологической близости древнерусских и западноевропейских городов и, соответственно, из чего следовал вывод о развитых коммунальных органах на Руси, главным из которых, по мнению приверженцев этой концепции, было вече. Русские города, так же, как и западноевропейские, вели борьбу за городские вольности; так же, как и в некоторых западноевропейских странах, в борьбе с «феодалами» (боярами), князья, стремившиеся к усилению своих позиций, опирались на города. С этой точки зрения рассматривался и социальный состав веча. С разными оттенками во взглядах эту концепцию в целом разделяли такие историки, как Б. Д. Греков, М. Н. Тихомиров, Л. В. Черепнин, В. Т. Пашуто, позднее Ю. А. Лимонов.

Во-вторых, в свое время еще С. В. Юшков предположил, что в Древнерусском государстве веча становятся «совещаниями основных феодальных групп или групп, так или иначе связанных с феодалами» ${ }^{3}$. Однако особенную популярность эта, условно говоря, «феодальная» концепция веча приобрела в 1960-1970-е гг., по мере распространения теории так называемого «государственного феодализма», которая, с одной стороны, признавала Древнюю Русь раннефеодальным государством, но с другой, отмечала специфику древнерусского феодализма. В той или иной

2. А. Е. Пресняков, Лекции по русской истории: Киевская Русь, М., 1993, с. 401.

3. С. В. Юшков, Очерки по истории феодализма в Киевской Руси, М.-Л., 1939, c. $197,216$. 
степени полагают, что вече состояло исключительно или почти исключительно из «феодалов», боярско-дружинной знати, В. Л. Янин, М. Б. Свердлов, П. П. Толочко, Т. Л. Вилкул и др. В. Л. Янин, например, оценивал новгородское вече так: «Новгородский вечевой строй является образцом феодальной демократии в ее русском боярском варианте» ${ }^{4}$.

В-третьих, в 1970-е гг. И. Я. Фроянов выдвинул и вместе со своими учениками (А. В. Майоровым, Ю. В. Кривошеевым и др.) стал активно пропагандировать «альтернативную» концепцию общественного строя Древней Руси, основанную на представлении об общинном характере древнерусской государственности, о подобных античным полисам городахгосударствах на Руси, где высшая власть принадлежала всему народу, собиравшемуся на веча - собрания «волощан»: всех свободных жителей волости, как горожан, так и селян.

Удивительно, что единственное монографическое исследование русского веча после труда Сергеевича появилось не в отечественной, а в зарубежной историографии. В силу причин, которые станут очевидны ниже, мы считаем необходимым остановится на нём подробнее. В своем сочинении, опубликованном в 1967 г., , немецкий славист Клаус Цернак подверг тщательному анализу практически все летописные данные, прямые и косвенные, о «городских собраниях» с IX по конец XV вв. Важнейшим достоинством его исследовательской методики нужно признать разумное использование компаративного подхода: русское вече изучается не как «вещь в себе», а в сопоставлении со схожими и исторически, вероятно, однородными явлениями у западных славян. Автор привлекает широкий круг латиноязычных памятников, в которых упоминаются placita, contiones, consilia и т. д. у сорбов, ободритов, лютичей, ранов, поморян, в раннесредневековой Польше. И хотя в итоге К. Цернак пришёл к неутешительному заключению о том, что результаты его исследования «лежат, вероятно, главным образом, в негативной плоскости и, в сущности, показывают, чем вече не было» ${ }^{6}$, монография немецкого учёного и по сей день не имеет себе равных как по охвату материала, так и по глубине и всесторонности его изучения. Несомненно, именно она должна в настоящее время служить отправной точкой для новых исследований данной проблематики.

Главные выводы К. Цернака вкратце могут быть сведены к двум положениям. Во-первых, отрицание непосредственной преемственности («континуитета») между городскими собраниями славянского средневековья и «племенными» собраниями догосударственной эпохи. Отрицает автор универсальный, общеславянский характер вечевых собраний, а на этой

\footnotetext{
4. В. Л. Янин, Новгородские посадники, М., 1962, с. 4.

5. K. Zernack, Die burgstädtischen Volksversammlungen bei den Ost- und Westslaven. Studien zur verfassungsgeschichtlichen Bedeutung des Veče, Wiesbaden, 1967.

6. Ibid., S. 268.
} 
основе - и популярную в историографиях славянских стран с XIX в. и до наших дней концепцию «вечевого строя», характеризующегося глубокими демократическими традициями (впервые якобы зафиксированными Прокопием Кесарийским в VI в.) Во-вторых, идея о том, что древнерусское вече представляет собой явление городское. По словам немецкого историка:

база для возникновения вечевого народного собрания была $[. .$.$] изначально,$ принимая во внимание как социальные движущие силы, так и политические причины, одна и та же : город как фактор земельной организации ${ }^{7}$.

Появление работы К. Цернака оказало далеко идущее воздействие на историографию. Большинство немецких учёных и сейчас полностью разделяют его выводы. Некоторые-же, по-видимому, полагают, что К. Цернак, так сказать, «закрыл» проблему и, характеризуя конкретные вечевые собрания с социальной точки зрения, часто предпочитают самостоятельному анализу источника ссылку на работу своего предшественника ${ }^{8}$. Между тем, в действительности, выводы К. Цернака отнюдь не являются общепринятыми.

Больше всего критических замечаний было высказано польскими рецензентами. Признавая заслуги немецкого слависта, Ст. Руссоцкий и Г. Лабуда высказали сомнения относительно некоторых слабо обоснованных, с их точки зрения, позиций К. Цернака. Главные их возражения могут быть сформулированы так: 1) отсутствие «континуитета» между городскими вечами и славянскими «племенными» собраниями, а также постулируемый немецким историком аристократический характер последних, столь же слабо обоснованы, как и романтическая концепция о славянской вечевой демократии; 2) К. Цернаком по неизвестной причине не привлечены источники по Чехии и Великой Моравии - важнейшим западнославянским регионам, а также по южным славянам; 3) по мнению Г. Лабуды, автор «часто и с напором» утверждает чисто городской характер древнерусских собраний, игнорируя то обстоятельство, что «городское вече могло быть последним звеном длинной цепи изменений». Заслуживает также большого внимания комментарий Г. Лабуды о том, что, противопоставляя разработанную на скудных славянских материалах слабо подкреплённую источниками концепцию аристократических «племенных» собраний столь же слабо подкреплённой источниками концепции древнеславянской «племенной» демократии, К. Цернак совершенно напрасно прошёл мимо

7. Ibid., S. 265.

8. Разнообразные примеры, когда в спорных или неясных случаях у немецких историков в качестве ultima ratio выступает апелляция к К. Цернаку, см., например W. Knackstedt, Moskau: Studien zur Geschichte einer mittelalterlichen Stadt, Wiesbaden, 1975, S. 27; C. Göhrke, «Bemerkungen zur altrussischen Stadt der frühen Teilfürstenzeit (Mitte des 11. bis Mitte des 12. Jahrhunderts)», in Beiträge zum hochmittelalterlichen Städtewesen, Köln-Wien, 1982, S. 228; G. Pickhan, Gospodin Pskov. Entstehung und Entwicklung eines städtischen Herrschaftszentrum in Altrußland, Berlin, 1992, S. 78 
типологически (хотя и не хронологически) близких сведениях о собраниях балтских «племён», прежде всего, пруссов 9 . При этом многие общие и частные выводы и, что самое главное, сама методика работы немецкого историка сомнений у рецензентов не вызывала.

Ещё более резкой критике позицию немецкого историка подверг Х. Ловмяньский в IV томе своего капитального труда Poczqtki Polski, посвящённому, вопреки своему названию, ранней истории не только Польши, но всего славянского мира, в том числе Древней Руси. Польский учёный весьма язвительно заметил, что выводы К. Цернака «следует отнести не только к трудностям интерпретации, которые автор встретил, борясь с источниками, но, прежде всего, к предвзятой концепции устройства власти у славянских племён, которую он пытается доказать» 10 . В целом позиция $\mathrm{X}$. Ловмяньского относительно древнерусского веча близка к концепции Б. Д. Грекова-М. Н. Тихомирова, предусматривавшей три этапа его эволюции: племенная демократия в догосударственную эпоху, угасание веча в Киевской Руси и новый расцвет уже как городского собрания в период раздробленности - с той лишь поправкой, по мнению польского историка, в $\mathrm{X}$ в. произошло не угасание, а «ослабление» веча ${ }^{11}$.

Поразительным и не поддающимся никакому объяснению остаётся тот факт, что и книга К. Цернака, и вся последующая дискуссия до сих пор находятся за пределами внимания отечественных медиевистов, занимающихся вечем. Так, И. Я. Фроянов (а также его ученики), уделяющие немало места «сравнению» Древнерусского государства с африканским племенем йоруба, тихоокеанскими папуасами и древнегреческими полисами, по-видимому, просто не знают о существовании предшественников, рассматривавших те же самые проблемы, но на гораздо более высоком научном уровне ${ }^{12}$. Единственным отечественным историком, отозвавшимся на работу К. Цернака, был В. Т. Пашуто, который в рецензии с не вполне академическим названием подверг её решительной критике, носившей

9. «Russocki St. Wiece w miastach Słowiańszczyzny Wschodniej i Zachodniej: Nowa próba wyjasnienia ich genezy i funkcji», Przeglad historyczny, Warszawa, 1968, T. LIX, Zeszyt 44, s. 750-755; G. Labuda, «Wczesnośredniowieczne wiece słowiańskie» Kwartalnik historyczny, Warszawa, 1969, Rocznik LXXVI, Nr. 4, s. 918-920.

10. H. Łowmiańsky, Początki Polski, Warszawa, 1970, T. IV, s. 101-102.

11. Ibid., s. 105.

12. Естественно, речь идёт о подлинном знании историографии. Так, например, современная украинская исследовательница Т. Л. Вилкул эпизодически ссылается на монографию К. Цернака по частным сюжетам, из чего может сложиться впечатление, что она разделяет концепцию немецкого историка, которая между тем прямо противоречит её идеям. Например, если К. Цернак полагал, что в древнерусском вече эпохи раздробленности активное участие принимали непривилегированные городские слои (die Unterschicht), то Т. Вилкул убеждена, что состав веча ограничивался только дружинной элитой (см.: Т. Л. Вилкул, «Дружина-вече», Государство и общество: История экономика, политика, право, 2002, № 1). 
отчасти научной, отчасти политический характер ${ }^{13}$. Вместе с тем В. Т. Пашуто, действительно, указал на некоторые слабые места в работе К. Цернака: отказ от обсуждения «неудобных» для его концепции известий; ничем не обоснованное доверие к украинской эмигрантской историографии, рассматривавшей «Галицкую державу» как нечто обособленное от остальной Руси и связанный с этим отказ рассматривать социальнополитическую активность горожан в Галицко-Волынском княжестве XIIIXIV вв. в общерусском контексте; игнорирование под предлогом «единичности» чрезвычайно интересных свидетельств о вечевых собраниях в Полоцкой земле, Смоленске и городах Владимирского великого княжества в XIV-XV вв. ${ }^{14}$.

К. Цернак ответил на критику: отдельно В. Т. Пашуто ${ }^{15}$ и польским рецензентам $^{16}$. Отстаивая свою главную позицию (неприятие теорий общеславянского демократического вечевого строя и представление о вече как о «городском собрании под руководством верхнего слоя»), он признал многие конкретные замечания и, в конце концов, был вынужден согласиться с возражениями польских историков на его реконструкции «племенных» собраний у восточных и западных славян. К. Цернак даже самокритично отметил (по поводу рецензии Ст. Руссоцкого): «ОН справедливо констатирует, что мои размышления о племенном времени [...] оставляют желать лучшего» ${ }^{17}$. Между тем, именно эти «размышления» лежали в основе выдвинутой К. Цернаком концепции «дисконтинуитета» между славянскими «племенными» собраниями и городским вечем Древней Руси. В связи с этим вызывает некоторое недоумение продолжающееся до сих пор некритическое воспроизведение немецкими славистами взглядов этого исследователя.

Важно и другое. По-видимому, никто из рецензентов не обратил внимания на существенные изъяны в методике работы К. Цернака с источниками, главным из которых является формалистический, терминологический подход. Немецкий историк недоценивал многозначность древнерусских понятий, даже таких общих, как «мужи» и «люди» и постулировал в корне неверное положение о том, что это якобы были наименования двух различных социальных категорий:

13. Справедливости ради, надо отметить, что и монография К. Цернака не вполне свободна от идеологии: введение, например, полно инвектив против панславистских и марксистских теорий политического строя славян, в то время, как мрачные эпизоды истории немецкого Ostforschung'а обходятся стороной (K. Zernack, op. cit., s. 3-12).

14. В. Т. Пашуто, «В ущерб истине (по поводу книги о русском вече)», История СССР, 1968, № 5 .

15. [K. Zernack], «Stellungnahme zu den Brief von V. T. Pašuto an H. Ludat», Jahrbücher für Geschichte Osteuropas, Wiesbaden, 1969, Neue Folge, Bd.17, H.1.

16. K. Zernack, «Fürst und Volk in ostslavischer Frühzeit», Forschungen zur osteuropäischen Geschichte, 1973, S. 18.

17. Ibid., S. 19. 
Как внутри, так и вне Киева в эпоху расцвета государства явственно присутствует основополагающая социальная дихотомия веча. Можно говорить о мужах и людях, верхнем и нижнем слое как о двух крупных социальных компонентах раннего веча ${ }^{18}$.

На практическом уровне это положение приводило к тому, что, если в летописном тексте К. Цернаку встречался «муж» он автоматически характеризовал его как представителя элиты, а если «человек» - как представителя «нижнего слоя». Естественно, этот искусственный и упрощённый подход неизбежно порождает ошибки при анализе описываемых в летописях сложных социально-политических коллизий, связанных с вечевыми собраниями. Наиболее острые споры по проблемам славянских «народных собраний» относятся к 1960-1970-х гг., однако они остаются остро дискуссионными и ныне, что убедительно продемонстрировано в относительно недавней статье чешского историка Й. Жемлички ${ }^{19}$.

Проведённые нами в последнее время исследования в области истории домонгольского веча, преимущественно ключевой её проблемы социального состава - показывают, на наш взгляд, следующее. Источники свидетельствуют о том, что в социально-политической жизни Древней Руси принимали участие какие-то общественные группы, отличные от княжескобоярско-дружинной элиты. При этом социально-политическую деятельность «киян» или «владимирцев», нужно всякий раз анализировать, для того, чтобы понять, какие именно социальные группы скрываются под такого рода наименованиями. Кроме того, нет смысла изучать «вече» или «совет» как абстрактные категории, «институты» в традиции историко-правовой науки XIX в. Надо исследовать действительные социально-политические отношения и уже в связи с этим разбирать применяющиеся к ним в русских летописях понятия. Если в летописных известиях о тех или иных проявлениях коллективной активности «киян», «новгородцев», «переяславцев» и т.д., или в сообщениях о «вече» нет конкретной информации о социальной природе этих феноменов, они не могут нам помочь пролить свет на участие в политической жизни Древней Руси недружинных слоев населения.

Что это за слои? По нашему мнению, помимо князей и боярскодружинной знати, это были, прежде всего, горожане. Никаких данных о самостоятельной политической активности в каких-либо формах сельского населения в летописях нет. Одновременно не находит подтверждения в источниках концепция о существовании такой социально-политической общности, как «волощане» или «людство» (в смысле всего свободного

18. Ibid., S. 12.

19. J. Žemlička, «Te ducem, te iudicem, te rectorem (Sněmovní shromáždění v časně stř̌edověkých Čechách - kontinuita či diskontinuita?», Český časopis historický, 1993, Roč. 91. 
населения городов и сел), и, как следствие, выглядят необоснованными все рассуждения относительно общинного народовластия, городов-государств, полисов и т.п. применительно к средневековой Руси. Древнерусские горожане не представляли собой нерасчлененную массу «общинников». Напротив, они были разделены на ряд социальных групп. Применительно к социально-политической деятельности, и, прежде всего, к вечу, их можно разделить на две категории. Первая - это, если говорить о раннем периоде (приблизительно до второй половины XII в.), дружинная элита. Если же говорить о периоде со второй половины XII в. до татаро-монгольского нашествия, - это представители знати, в разное время утратившие непосредственную связь с дружинной организацией и «осевшие» в городе, а также купцы. Лица, входившие в эту категорию, постоянно управляли городом и обладали в целом весьма широкими полномочиями. Однако, основная масса городского населения не была отделена от управления городом, но вмешивалась в него эпизодически, особенно в случае каких-либо катаклизмов, затрагивавших интересы всех слоев общества. Остальные слои древнерусского населения (сельские жители, челядь, смерды) никакого участия в самостоятельной социально-политической деятельности, и в том числе в вече, не принимали. Можно лишь допустить эпизодическое подключение к социально-политической деятельности горожан жителей сельской округи, непосредственно примыкавшей к городу. Впрочем, это было исключением, подтверждавшим правило: единственным центром политической жизни в Древней Руси был город.

Принципиально важно, что предлагаемый нами подход к данной теме предусматривает изучение не только домонгольского, но и более позднего периода - в отличие от характерного для историографии ограничения. Это, во-первых, может позволить проследить судьбу традиционных древнерусских социально-политических институтов в XIV-XV вв., а, вовторых, и это главное, поможет ретроспективно расширить источниковую базу.

Далеко не исчерпаны возможности изучения социально-политической деятельности горожан в Северо-Восточной Руси во второй половине XIIIXV вв. Обычно сообщения о вечевых собраниях 1262, 1327, 1382 гг. в различных городах великого княжества Владимирского рассматривались сквозь призму политической истории, в особенности в рамках борьбы «народных масс» против ордынского ига. Однако со времён Сергеевича эти известия не изучались в комплексе с сообщениями домонгольской эпохи. Между тем, даже предварительные наблюдения показывают, что, с точки зрения социального состава веча, больших изменений в Северо-Восточной Руси, вероятно, не произошло: вече по-прежнему оставалось одним из проявлений социально-политической деятельности всех свободных горожан. Другое дело, что постепенно меняется место и значение веча в политической жизни государственных образований, входивших во Владимирское великое княжество. По мере усиления княжеской власти и складывания монархии 
вече из феномена, хотя и в определённой мере экстраодинарного, но всё же, условно говоря, «легитимного» в общественном сознании (так, летописцы домонгольского времени рассматривают вечевые собрания, даже заканчивающиеся изгнанием князей, как вещь совершенно естественную) превращается в явление исключительное, часто осуждаемое (особенно в московском летописании). При этом, конечно, для реконструкции событий этого периода необходимо постоянно учитывать взаимоотношения летописных текстов, выделяя наиболее ранние. Это исключительно важно, например, для правильного понимания событий 1327 г. в Твери и 1382 г. в Москве, о которых в разных летописных традициях имеются повествования с прямо противоположными оценками и не совпадающими фактами.

Не всё ясно с социально-политической сущностью веча в Новгороде и Пскове в послемонгольское время. Преобладающая в последнее время точка зрения о его чисто боярском составе, по крайней мере, для XIII в. не находит подтверждения в источниках. Данные, прежде всего новгородских летописей, показывают, что социальный состав веча на Северо-Западе Руси тогда был значительно шире и, по-видимому, включал всё свободное городское население (при этом, конечно, фактически боярство играло первенствующую роль). С другой стороны, именно в свете новгородских и псковских известий XIII-XV вв. особенно чётко выявляется надуманность концепций о древнерусской демократии, общинном характере государственности, социальной однородности населения и т. п.

Определённые надежды можно возлагать на практически не привлекавшиеся к исследованию этой темы материалы, связанные с территориями Южной, Юго-Западной и Западной Руси, оказавшимися после монголо-татарского нашествия в составе Великого княжества Литовского, а также Польши. На необходимость такого исследования уже обращал внимание Б. Н. Флоря ${ }^{20}$. При этом именно здесь есть надежда на открытие новых архивных источников. Так, недавно обнаруженный М. М. Кромом в петербургской части бывшего Радзивилловского архива список расспросных «речей» беглецов из Пскова в Великое княжество Литовское, датирующийся сетнябрём 1534 г., существенно уточняет наши представления об истории псковского веча. Беглые псковичи, некие дьяк Родивон, Гриша и Тонкий, показали, что к моменту их бегства детей боярских во Пскове

зостало толко сорок голов, а болши тых нияких людей во Пскове нет, кроме купцов, которыи з Москвы приведены, а чорных людей-пскович. Ино деи тыи люди чорныи часто ся сходят у вечо, чого ж им намесники и дьяки боронят и на торгу кликати кажуть, жебы ся у вечо не сходили, бо не ведают, што думают $^{21}$.

20. Б. Н. Флоря, «Историческая традиция об общественном строе средне-векового Полоцка», Отечественная история, 1995, № 5.

21. Памятники истории Восточной Европь: Источники XV-XVII вв., М.-Варшава, 2002, T. VI: Радзивилловские акты из собрания Российской национальной 
Из этого краткого сообщения следует ряд важнейших выводов. Отметим пока следующее. Вече в Пскове было настолько обыденным явлением, что даже после утраты независимости псковичи продолжали собираться на вечевые собрания. Вече явно не было «институтом» власти в нашем сегодняшним понимании, а, скорее, «житейским» мероприятием, игравшим при этом важную социально-политическую роль. И самое главное: этот документ убедительно и безусловно доказывает, что даже в XVI в. в вече участвовали и притом весьма активно, не только представители элиты, «феодалы», знать и т.д., но и рядовые горожане. Более того, в условиях, когда собственного элитного слоя во Пскове после присоединения к Москве не осталось, чёрные люди-псковичи стали практически единственными участниками вечевых собраний, которые, с их точки зрения (но, конечно, вразрез с позицией московских властей), видимо, сохраняли легитимность. С другой стороны, даже при таких обстоятельствах на этих самодеятельных вечах мы не видим присутствия сельских жителей.

Значительный интерес с нашей точки зрения также представляет компаративный анализ: рассмотрение различных форм социальнополитической активности русских горожан в широком общеевропейском контексте, что может открыть новые перспективы для исследований. Определённые попытки сравнительного анализа социально-политических институтов, прежде всего, у восточных и западных славян, нами уже предприняты $^{22}$.

Российская Академия Наук

Институт российской истории

lukinpavel@yandex.ru

plukin@aport.ru

библиотеки: Первая половина XVI в., с. 115. Выражаем искреннюю благодарность М. М. Крому за указание данного документа.

22. П. В. Лукин, «Народные собрания» у восточных и западных славян: возможности сравнительного анализа», Древняя Русь. Bопросы медиевистики, 2004, №3. 